\title{
A review of the anti-tumor effect of the combined administration of a cyclooxygenase- 2 selective inhibitor and a non-specific immunostimulant protein-bound polysaccharide on an advanced colon cancer model using colon cancer cell lines
}

\author{
KENJI KATSUMATA, NORIYUKI MUSIAKE, KENTARO SHIBUYA, TAKAHIRO NAKAJIMA, \\ MASATO WATANABE, MOTOYUKI SASAKI and YASUYUKI SUGIYAMA \\ Department of Surgery, Mizonokuchi Hospital of Teikyo University, Kanagawa, Japan
}

Received November 22, 2010; Accepted February 28, 2011

DOI: 10.3892/ol.2011.279

\begin{abstract}
The anti-tumor effect of a cyclooxygenase (COX)-2 selective inhibitor or a non-specific immunostimulant (PSK) alone, as well as the anti-tumor effect of their combined administration were examined on a hepatic metastasis model of colon cancer using a colon 26 cell line (CT26) and its highly metastatic variant. Anti-tumor effects were assessed by the number of hepatic metastases. Serum MMP-9, TGF- $\beta$ and IL-6 were also measured. In a preliminary experiment, cells $\left(5 \times 10^{5}\right)$ of a mouse colon cancer 26 cell line (CT26) and its highly metastatic variant were implanted below the splenic capsule in $\mathrm{BALB} / \mathrm{c}$ and $\mathrm{CDF} 1$ mice. The number of hepatic metastatic CT26 cell lesions in the CDF1 mice of the nonspleen-removed group at 2 weeks was found to be optimum for the experiments. Although no significant difference was found, etodolac treatment showed the highest inhibitory effect on the number of hepatic metastases at a concentration of $30 \mathrm{mg} / \mathrm{kg}$. In contrast, intraperitoneal administration of $50 \mathrm{mg} /$ $\mathrm{kg}$ PSK showed an inhibitory effect on hepatic metastases, but a significant difference was not observed. PSK $(p=0.002)$ or the combined use of etodolac and PSK $(\mathrm{p}=0.001)$ exhibited a significant inhibition of the number of hepatic metastases. In addition, MMP-9 was significantly inhibited by the single use of etodolac or PSK, and was inhibited with an additive effect by the combined use of etodolac and PSK. IL- 6 and TGF- $\beta$ were significantly inhibited following the combined use of etodolac and PSK. In conclusion, etodolac did not exhibit any significant hepatic metastasis inhibitory effect, whereas it significantly reduced the MMP-9 level. PSK reduced both the
\end{abstract}

Correspondence to: Dr Kenji Katsumata, Department of Surgery, Mizonokuchi Hospital of Teikyo University, 3-8-8 Mizonokuchi Takatsuku, Kawasaki, Kanagawa 2138507, Japan

E-mail: katsuken@med.teikyo-u.ac.jp

Key words: colon cancer model, cyclooxygenase-2 selective inhibitor, protein-bound polysaccharide number of hepatic metastases and MMP-9. Combined use of etodolac and PSK did not show any additive effect in the inhibition of the number of hepatic metastases, whereas it inhibited MMP-9, TGF- $\beta$ and IL- 6 , suggesting the benefit of a combined effect.

\section{Introduction}

Expression of cyclooxygenase (COX)-2 is observed in colon polyps or colon cancer tissues, and it has been confirmed that microsomal PGES-1, which lies downstream of COX-2 and is involved in the synthesis of prostaglandin $\mathrm{E}_{2}\left(\mathrm{PGE}_{2}\right)$, plays an important role in oncogenesis $(1,2)$. It was reported that tumor growth by $\mathrm{PGE}_{2}$ may be the result of an increase in the production of vascular endothelial growth factor, the growth of epithelial cells or an increase in resistance to apoptosis (3). In particular, $\mathrm{PGE}_{2}$ was found to induce the expression of the matrix metalloproteinases (MMP), resulting in the release of transforming growth factor- $\alpha$ (TGF- $\alpha$ ) (4), an EGFR ligand, and stimulating EGFR, both of which are blocked by the COX-2 inhibitor (5). It was clinically shown that the COX-2 inhibitor suppressed the occurrence of colon cancer (6) in patients treated with aspirin and decreases the recurrence of colon cancer (7). Thus, the COX-2 inhibitor is expected to prevent colon polyps and inhibit the metastasis of colon cancer. It is also known to have an inhibitory effect on cytokines such as interleuken (IL)-6.

Protein-bound polysaccharide (PSK) is a protein polysaccharide extracted and refined from Trametes versicolor with a molecular weight of approximately 100,000. It is known to have pharmacologic actions including inhibition of the production of immunosuppressive agents, enhancement of the production or inhibition of the excessive production of cytokines, and direct action on cancer cells. Cytokines are believed to inhibit IL-1, IL-6 and IL-8, or the expression of TGF- $\beta$, thereby inhibiting the expression of MMPs and suppressing the invasion/metastasis of cancer (8). The two drugs are based on completely different mechanisms of pharmacological effect. However, a common effect is expected. The anti-tumor and cytokine inhibitory effects have been demonstrated by 
respective experiments, whereas an additive or synergistic effect of the two drugs has yet to be reported. Therefore, in the present study, the effects of the COX-2 inhibitor, etodolac, and a non-specific immunostimulant, PSK, were investigated using in vivo experiments.

\section{Materials and methods}

Mice. BALB/c or CDF1 male mice were purchased at 6 weeks of age, acclimatized for 7 days, and subsequently used for the experiments.

Preparatory experiment schedule. In the treatment experiment, a hepatic metastasis model was constructed by infusing cancer cells in BALB/c or CDF1 male mice below the splenic capsule where etodolac and PSK were administered. Cells $\left(5 \times 10^{5}\right)$ of the mouse colon cancer 26 cell line (CT26) and its highly metastatic variant were implanted below the splenic capsule. Three days after implantation, a spleen-removed group and a non-spleen-removed one were produced and the hepatic metastasis model was designed. Two or 3 weeks after cell implantation, the number of hepatic metastases in each group was measured, and the optimal model was determined.

Using the optimal model, etodolac suspended in $1 \%$ methylcellulose solution was administered at 5, 10, 20 and $30 \mathrm{mg} / \mathrm{kg}$ from day 1 after cell implantation ( $n=10$ mice/group). From the following day, etodolac was administered 15 times daily, and the animals were sacrificed on day 16. At the time of sacrifice, the inhibitory rate was determined by calculating the number of hepatic metastases, and the optimal dosage of etodolac was determined.

Using the optimal model, PSK was dissolved in physiological saline. PSK was administered intraperitoneally (25 or $50 \mathrm{mg} / \mathrm{kg}$ ) or orally (1000 mg/kg) ( $\mathrm{n}=7$ mice/group). From the day following implantation, PSK was administered intraperitoneally on alternate days 3 times per week, and orally on 5 consecutive days per week. Animals were sacrificed on day 16 following cell implantation, the number of hepatic metastases was measured, and the optimal dosage of PSK was determined.

Experiments. The optimal dosages were determined using the preparatory experiments, and etodolac and PSK were administered singly or in combination, for 2 weeks from the day following cell implantation ( $\mathrm{n}=8 \mathrm{mice} / \mathrm{group})$. The mice were sacrificed one day after completion of the administration schedule (on day 16), and the inhibitory rate of tumor growth compared with that of the solvent control group was determined from the number of hepatic metastases. Regarding the group composition, each group consisted of 10 mice: the solvent control group, which included a forced oral administration group of $0.5 \%$ methylcellulose solution, the etodolac single administration group, the PSK single intraperitoneal administration group and the group of combined administration of etodolac + PSK.

Biochemical measurement. Each animal was sacrificed $3 \mathrm{~h}$ after the final administration of each drug, and serum samples were obtained. The samples were cryostatically preserved $\left(-20^{\circ} \mathrm{C}\right.$ or below) until measurement of the levels of MMP-9, TGF-B, and IL-6.
Measurement of MMP-9. The Quantikine Mouse pro-MMP-9 Immunoassay (R\&D Systems, Inc., MN, USA) is a 4.5-h solid phase ELISA designed to measure free and TIMP-1-bound mouse pro-MMP-9 in cell culture supernatants, mouse serum and platelet-poor plasma. It contains NS0-expressed recombinant mouse pro-MMP-9 showing dose-response curves that are parallel to the standard curves obtained using the recombinant Quantikine kit standards, indicating that the Quantikine kit can be used to determine relative levels of natural mouse pro-MMP-9. The measurement method is as follows. All of the reagents were brought to room temperature. Reagents and samples were prepared according to the manufacturer's instructions. Unused components were returned to storage temperature as indicated in the instructions. Assay diluent $(50 \mu \mathrm{l})$ was added to each well followed by the addition of $50 \mu \mathrm{l}$ of the standard, control or sample to each well. The plate was covered, and incubation was carried out for $2 \mathrm{~h}$ at room temperature in a shaker. Each well was aspirated and washed four times and substrate solution $(100 \mu \mathrm{l})$ was then added to each well. Incubation was carried out for $30 \mathrm{~min}$ at room temperature in the dark, and $100 \mu \mathrm{l}$ of stop solution was added to each well. The optical density was read at $450 \mathrm{~nm}$ (correction wavelength set at 540 or $570 \mathrm{~nm}$ ).

Measurement of IL-6. The Quantikine Mouse IL-6 Immunoassay (R\&D Systems) is a 4.5 -h solid-phase ELISA designed to measure mouse IL-6 in cell culture supernatants, serum and plasma. It contains $E$. coli-expressed recombinant mouse IL-6 and antibodies raised against the recombinant factors. This immunoassay has been shown to accurately quantitate the recombinant mouse IL-6. The results obtained using natural mouse IL- 6 showed dose response curves that are parallel to the standard curves obtained using the Quantikine Mouse kit standards.

These results indicate that the Quantikine Mouse IL-6 Immunoassay kit can be used to determine relative mass values for natural mouse IL-6. The measurement method is as follows. Reagents, samples and standard dilutions were prepared as described in the previous sections. Excess microplate strips were removed from the plate frame, returned to the folic pouch containing the dessicant pack and resealed. Assay diluent RD1-14 (50 $\mu 1)$ was added to the center of each well. Notably, RD1-14 contains undissolved material even when mixed well before and during use. Standard, control or sample $(50 \mu \mathrm{l})$ was added to the center of each well, which was covered with the adhesive strip provided and mixed by gently tapping the plate frame for $1 \mathrm{~min}$. Incubation was carried out for $2 \mathrm{~h}$ at room temperature. Plate layouts were provided to record standards and samples assayed. Each well was aspirated and washed, repeating the process four times for a total of five washes. Washing was performed by filling each well with wash buffer $(400 \mu \mathrm{l})$ using a squirt bottle, manifold dispenser or autowasher. The complete removal of liquid at each step is essential to good performance. After the last wash, any remaining wash buffer was removed by aspirating or decanting. The plate was inverted and blotted against clean paper towels. Mouse IL-6 conjugate $(100 \mu \mathrm{l})$ was added to each well, which was covered with a new adhesive strip. Incubation was carried out for $2 \mathrm{~h}$ at room temperature. Aspiration/wash was repeated as in step 5, and $100 \mu \mathrm{l}$ of stop solution was added to each well. Incubation 
Table I. Number of hepatic metastases in each group.

\begin{tabular}{lcccc}
\hline & $\begin{array}{c}\text { Non-spleen-removed } \\
(2 \text { weeks })\end{array}$ & $\begin{array}{c}\text { Spleen-removed } \\
(2 \text { weeks })\end{array}$ & $\begin{array}{c}\text { Non-spleen-removed } \\
(3 \text { weeks })\end{array}$ & $\begin{array}{c}\text { Spleen-removed } \\
(3 \text { weeks })\end{array}$ \\
\hline $\begin{array}{l}\text { BALB/c mice infused with a highly } \\
\text { metastatic variant of the CT26 cell } \\
\text { line }\end{array}$ & $5.0 \pm 7.0$ & $63.8 \pm 54.8$ & $51.0 \pm 42.4$ & $100 \pm 0$ \\
$\begin{array}{l}\text { BALB/c mice infused with the } \\
\text { CT26 cell line }\end{array}$ & $8.7 \pm 6.1$ & $8.0 \pm 12.1$ & $89.7 \pm 17.9$ & $41.7 \pm 34.4$ \\
$\begin{array}{l}\text { CDF1 mice infused with a highly } \\
\text { metastatic variant of the CT26 cell }\end{array}$ & $1.0 \pm 1.0$ & $21.0 \pm 15.4$ & $74.7 \pm 26.6$ & $51.0 \pm 43.7$ \\
line & & & & \\
$\begin{array}{l}\text { CDF1 mice infused with the CT26 } \\
\text { cell line }\end{array}$ & $43.3 \pm 28.5$ & $30.7 \pm 31.7$ & $88.0 \pm 25.2$ & $96.0 \pm 6.9$ \\
\hline
\end{tabular}

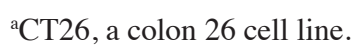

was carried out for $30 \mathrm{~min}$ at room temperature in the dark, and then $100 \mu 1$ of stop solution was added to each well. The plate was gently tapped to ensure thorough mixing. The optical density of each well was determined within $30 \mathrm{~min}$, using a microplate reader set to $450 \mathrm{~nm}$. When the wavelength correction was available, it was set to 540 or $570 \mathrm{~nm}$. When the wavelength correction was not available, the readings at 540 or $570 \mathrm{~nm}$ were subtracted from the readings at $450 \mathrm{~nm}$ to correct for optical imperfections in the plate. Readings taken directly at $450 \mathrm{~nm}$ without correction may be higher and less accurate.

Measurement of TGF- $\beta$. The Quantikine Mouse TGF- $\beta$ Immunoassay (R\&D Systems) measures TGF- $\beta$ in cell culture supernatants, mouse serum and platelet-poor plasma. The measurement method is as follows. Sample or standard $(100 \mu \mathrm{l})$ was added to reagent diluent or an appropriate diluent per well, which was covered with an adhesive strip and incubated for $2 \mathrm{~h}$ at room temperature. Aspiration/wash was repeated as in step 2 of plate preparation, and $100 \mu \mathrm{l}$ of the substrate dilution of Streptavidin-HRP was added to each well. The plate was covered and incubated for $20 \mathrm{~min}$ at room temperature in the dark. Stop solution was added to each well. The plate was gently tapped to ensure thorough mixing. The optical density of each well was determined immediately using a microplate reader set to $450 \mathrm{~nm}$. When the wavelength correction was available, it was set to 540 or $570 \mathrm{~nm}$. When the wavelength correction was not available, the readings at $450 \mathrm{~nm}$ were substracted to correct for optical imperfections in the plate. Readings made directly at $450 \mathrm{~nm}$ without correction may be higher and less accurate.

The animal experiments were conducted in accordance with the Guideline for Animal Experiments of Tokyo Medical University.

Statistical analysis. Statistical analysis was conducted using the Student's t-test. $\mathrm{P} \leq 0.05$ was considered to be a statistically significant difference. The results are provided as mean $\pm \mathrm{SD}$.

\section{Results}

\section{Number of hepatic metastases}

$B A L B / c$ mice infused with a highly metastatic variant of the colon 26 cell line (CT26). The number of hepatic metastases was 5.0 \pm 7.0 in the non-spleen-removed group at 2 weeks, $68.3 \pm 54.8$ in the spleen-removed group at 2 weeks, $51.0 \pm 42.4$ in the non-spleen-removed group at 3 weeks and $100 \pm 0$ in the spleen-removed group at 3 weeks.

$B A L B / c$ mice infused with CT26 cells. The number of hepatic metastases was $8.7 \pm 6.1$ in the non-spleen-removed group at 2 weeks, $8.0 \pm 12.1$ in the spleen-removed group at 2 weeks, $89.7 \pm 17.9$ in the non-spleen-removed group at 3 weeks and $41.7 \pm 34.4$ in the spleen-removed group at 3 weeks.

CDF1 mice infused with a highly metastatic variant of CT26 cells. The number of hepatic metastases was $1.0 \pm 1.0$ in the non-spleen-removed group at 2 weeks, $21.0 \pm 15.4$ in the spleen-removed group at 2 weeks, $74.7 \pm 26.6$ in the non-spleen-removed group at 3 weeks, and $51.0 \pm 43.7$ in the spleen-removed group at 3 weeks.

CDF1 mice infused with CT26 cells. The number of hepatic metastases was $43.3 \pm 28.5$ in the non-spleen-removed group at 2 weeks, $30.7 \pm 31.7$ in the spleen-removed group at 2 weeks, $88.0 \pm 25.2$ in the non-spleen-removed group at 3 weeks and $96.0 \pm 6.9$ in the spleen-removed group at 3 weeks.

Some individual mice had $>100$ metastases, which were judged to be impossible to evaluate. In BALB/c and CDF1 mice without removal of the spleen, the highly metastatic variant of the colon 26 cell line and CT26 cells at 2 weeks had $\leq 100$ metastases. However, in the CDF1 mice, a large number of hepatic metastatic lesions of CT26 cells were observed, which was regarded as the optimal model (Table I).

Effect of etodolac treatment. Regarding the effect of etodolac on the hepatic metastatic model using CT26 cells, the number of hepatic metastases was $73.5 \pm 10.2$ in the control group, $73.1 \pm 13.3$ in the $5 \mathrm{mg} / \mathrm{kg}$ etodolac group, $84.4 \pm 10.7$ 


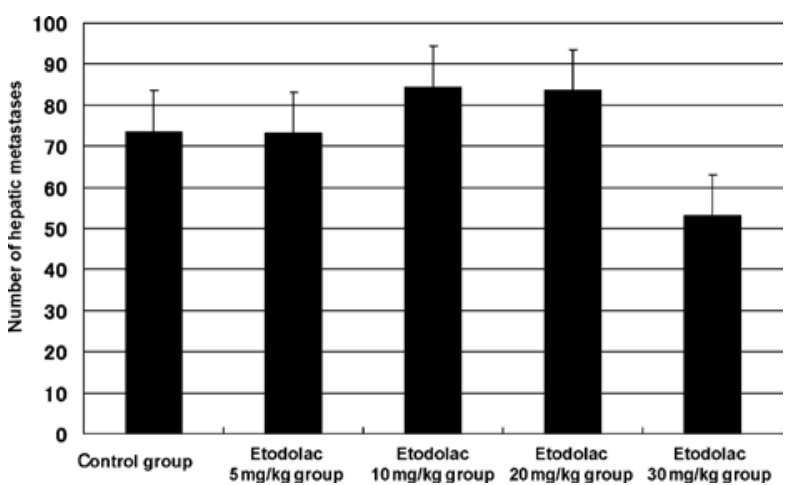

Figure 1. Effect of etodolac on the hepatic metastatic model using the CT26 cell line. No significant difference was noted, although the greatest inhibitory effect was observed at $30 \mathrm{mg} / \mathrm{kg}$.

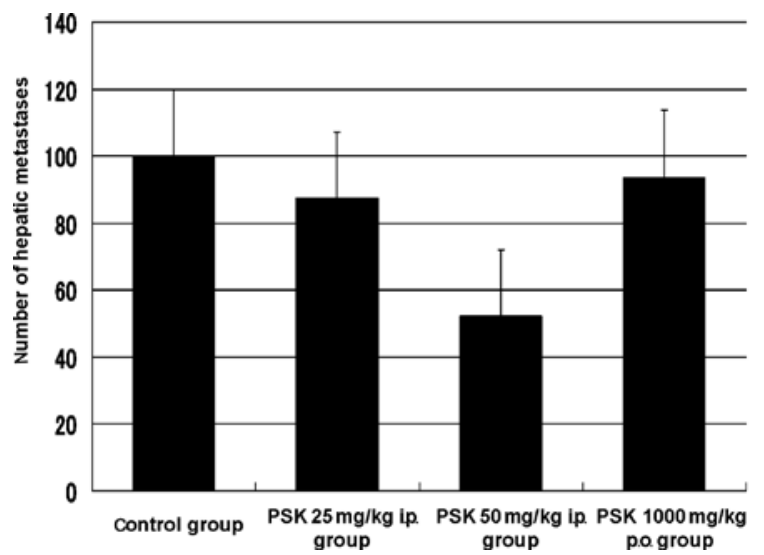

Figure 2. Effect of PSK on the hepatic metastatic model using the CT26 cell line. Although no significant difference was noted, the greatest inhibitory effect was observed at $50 \mathrm{mg} / \mathrm{kg}$ intraperitoneal (i.p.) administration of PSK. The inhibitory rate was $47.8 \%$. p.o., oral administration.

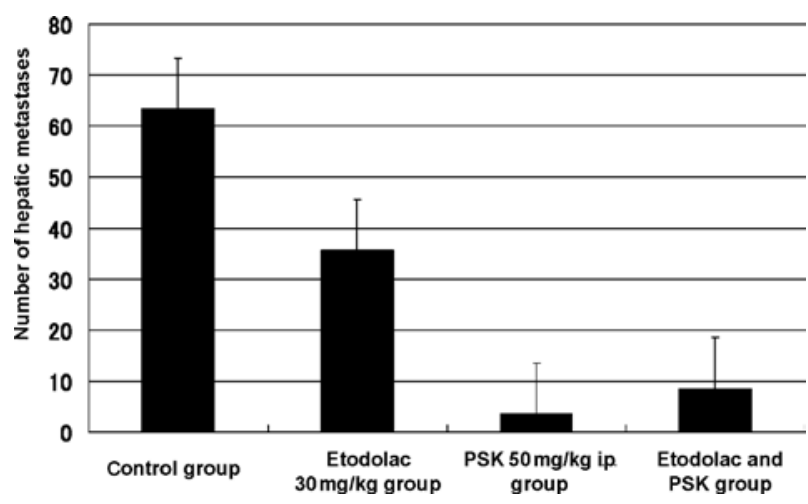

Figure 3. Effect of etodolac and PSK on the hepatic metastatic model using the CT26 cell line. No significant difference was noted between the control and PSK groups $(\mathrm{p}=0.002)$, and the etodolac and PSK group ( $\mathrm{p}=0.001)$. i.p., intraperitoneally.

in the $10 \mathrm{mg} / \mathrm{kg}$ group, $83.5 \pm 9.3$ in the $20 \mathrm{mg} / \mathrm{kg}$ group and $53.1 \pm 13.2$ in the $30 \mathrm{mg} / \mathrm{kg}$ group. The inhibitory rate was $0.7,-14.8,-13.6$ and $27.8 \%(\mathrm{p}=0.2)$, respectively. Although no significant difference was observed, the highest inhibitory

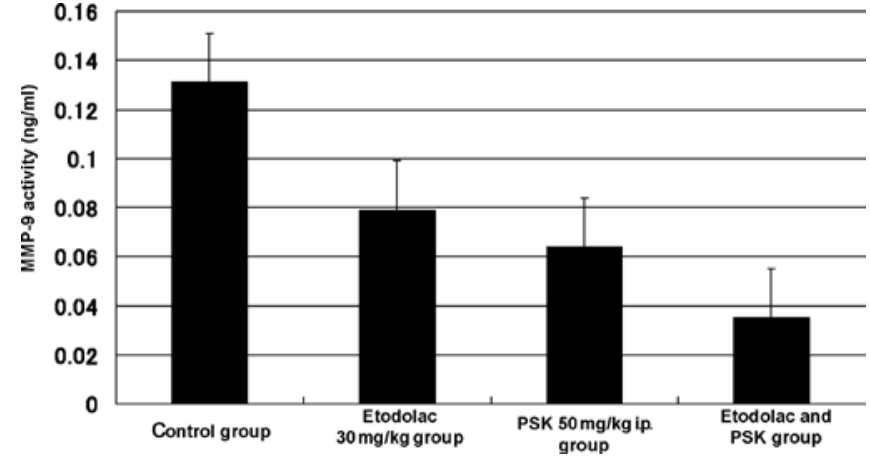

Figure 4. Effect of etodolac and PSK on MMP-9 activity in mouse serum. There was a significant difference between the control group and etodolac group $(\mathrm{p}=0.022)$, PSK group $(\mathrm{p}=0.003)$, and the etodolac and PSK group $(\mathrm{p}=0.001)$.

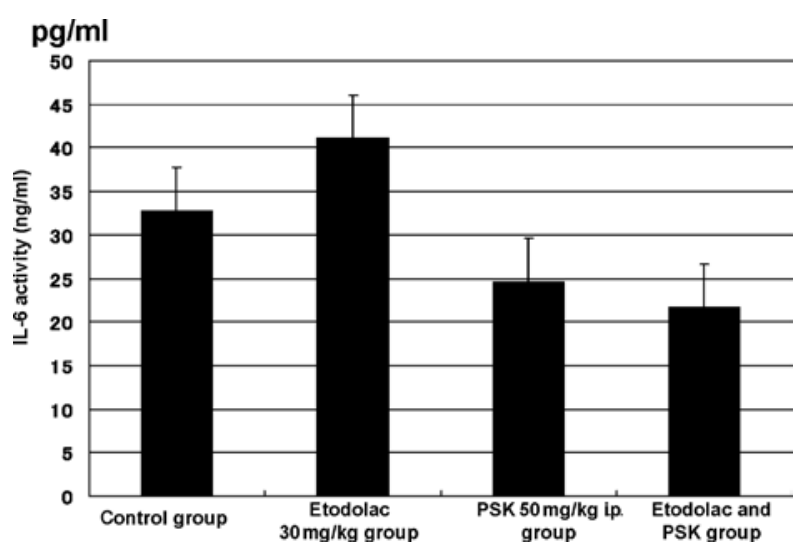

Figure 5. Effect of etodolac and PSK on IL-6 activity in mouse serum. There was a significant difference between the control group and the etodolac and PSK group $(\mathrm{p}=0.023)$.

effect was observed at $30 \mathrm{mg} / \mathrm{kg}$ etodolac, which was regarded as the optimal dosage (Fig. 1).

Effect of PSK treatment. Regarding the effect of PSK on the hepatic metastatic model using CT26 cells, the number of hepatic metastases was $100.0 \pm 0$ in the control group $(n=7)$, $87.3 \pm 12.7$ in the $25 \mathrm{mg} / \mathrm{kg}$ intraperitoneal administration PSK group, $52.2 \pm 18.0$ in the $50 \mathrm{mg} / \mathrm{kg}$ intraperitoneal administration PSK group and $93.0 \pm 7.0$ in the $1000 \mathrm{mg} / \mathrm{kg}$ oral administration PSK group. The inhibitory rate was $12.7,47.8$ $(\mathrm{p}=0.3)$ and $7.0 \%$, respectively. Although no significant difference was noted, the highest inhibitory effect was observed at $50 \mathrm{mg} / \mathrm{kg}$ intraperitoneal administration of PSK, which was regarded as the optimal dosage (Fig. 2).

Combination of etodolac and PSK. Regarding the number of hepatic metastases following administration of $30 \mathrm{mg} / \mathrm{kg}$ etodolac, $50 \mathrm{mg} / \mathrm{kg}$ intraperitoneal administration of PSK, and the combination of etodolac and PSK, the number of hepatic metastases was $63.3 \pm 12.9$ in the control group, 35.6 \pm 12.0 in the etodolac group, $3.5 \pm 1.0$ in the PSK group, and 8.5 \pm 4.6 in the etodolac and PSK group. The inhibitory rate of hepatic metastasis was $2.2 \%$ in the etodolac group, $94.5 \%(p=0.002)$ 


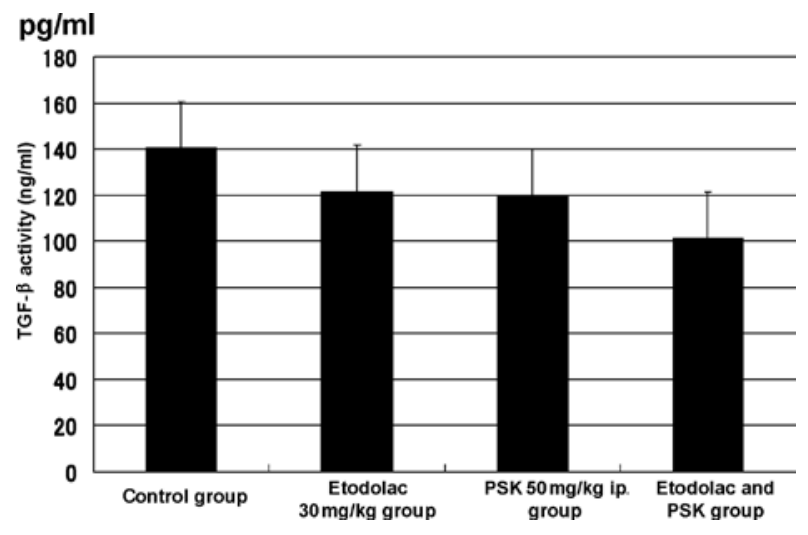

Figure 6. Effect of etodolac and PSK on TGF- $\beta$ activity in mouse serum. Aa significant difference was noted between the control group and the etodolac and PSK group $(\mathrm{p}=0.015)$.

in the PSK group and $86.6 \%$ in the etodolac and PSK group $(\mathrm{p}=0.001)$ (Fig. 3).

Biochemical measurement. The MMP-9 level was $0.131 \pm 0.049 \mathrm{ng} / \mathrm{ml}$ in the control group, $0.079 \pm 0.030 \mathrm{ng} / \mathrm{ml}$ $(\mathrm{p}=0.022)$ in the $30 \mathrm{mg} / \mathrm{kg}$ oral administration etodolac group, $0.064 \pm 0.021 \mathrm{ng} / \mathrm{ml}(\mathrm{p}=0.003)$ in the $50 \mathrm{mg} / \mathrm{kg}$ intraperitoneal administration PSK group, and $0.035 \pm 0.009 \mathrm{ng} / \mathrm{ml}(\mathrm{p}=0.001)$ in the intraperitoneal administration of the combination of etodolac $(30 \mathrm{mg} / \mathrm{kg}$ ) and PSK (50 mg/kg) group (Fig. 4). The IL-6 level was $32.75 \pm 10.028 \mathrm{pg} / \mathrm{ml}$ in the control group, $41.095 \pm 14.534 \mathrm{pg} / \mathrm{ml}$ in the $30 \mathrm{mg} / \mathrm{kg}$ oral administration etodolac group, $24.556 \pm 5.739 \mathrm{pg} / \mathrm{ml}$ in the $50 \mathrm{mg} / \mathrm{kg}$ intraperitoneal administration PSK group, and 21.648 $\pm 5.733 \mathrm{pg} /$ $\mathrm{ml}(\mathrm{p}=0.023)$ in the intraperitoneal administration of the combination of etodolac $(30 \mathrm{mg} / \mathrm{kg})$ and PSK $(50 \mathrm{mg} / \mathrm{kg})$ group (Fig. 5). The TGF- $\beta$ level was $140.700 \pm 27.455 \mathrm{pg} / \mathrm{ml}$ in the control group, $121.713 \pm 44.992 \mathrm{pg} / \mathrm{ml}$ in the $30 \mathrm{mg} / \mathrm{kg}$ oral administration etodolac group, $120.015 \pm 29.928 \mathrm{pg} / \mathrm{ml}$ in the $50 \mathrm{mg} / \mathrm{kg}$ intraperitoneal administration PSK group and $101.441 \pm 28.909 \mathrm{pg} / \mathrm{ml}(\mathrm{p}=0.015)$ in the intraperitoneal administration of the combination of etodolac $(30 \mathrm{mg} / \mathrm{kg})$ and PSK (50 mg/kg) group (Fig. 6).

\section{Discussion}

Regarding the involvement of COX-2 in carcinogenesis, the contribution of $\mathrm{Bcl}-2$ by the $\mathrm{PGE}_{2}$ production pathway, an increase in the invasiveness of cancer cells/vascularization by the production of vascular growth factors, VEGF and bFGF, and inhibition of the immunological surveillance mechanism have been suggested (9). The expression of COX-2 in colon polyps, colon cancer tissue, and interstitial cells has been confirmed, and it is known that microsomal PGES-1, which lies downstream of COX-2 and is involved in the synthesis of $\mathrm{PGE}_{2}$, plays an important role in oncogenesis. In particular, $\mathrm{PGE}_{2}$ is believed to induce the expression of matrix metalloproteinases (MMP), resulting in the release of transforming growth factor- $\alpha$ (TGF- $\alpha$ ), an EGFR ligand, thus stimulating EGFR (4). It has been reported that tumor growth caused by $\mathrm{PGE}_{2}$ may increase the production of vascular endothelial growth factor and may cause the growth of epidermal cells or an increase in resistance to apoptosis. It has been clinically demonstrated that COX-2 inhibitor suppresses the occurrence of colon polyps in patients treated with aspirin (5) and inhibits the recurrence of colon cancer (6). COX-2 also causes chronic inflammation and inhibits the production of IL-6, which increases as cancer advances (10). A COX-2 inhibitor, based on the inhibitory effect of such actions, is expected to prevent colon polyps and inhibit the metastasis of colon cancer. The APPROVe clinical trial was conducted to investigate the prevention of colon polyps, while the VICTOR clinical trial was conducted to evaluate the inhibition of the recurrence of colon cancer of the COX-2 inhibitor. However, both clinical trials ended without obtaining signficant results due to adverse cardiovascular side effects $(11,12)$.

Protein-bound polysaccharide, PSK, is a protein polysaccharide extracted and refined from Trametes versicolor with a molecular weight of approximately 100,000. PSK is known to have pharmacologic actions including the inhibition of the production of immunosuppressive agents, an increase in the production or inhibition of the excessive production of cytokines, and direct action on cancer cells. It is considered that cytokines inhibit IL-1, IL-6, and IL-8 or the expression of TGF- $\beta$, thereby inhibiting the expression of MMPs, and suppressing the invasion/metastasis of cancer (8).

Although the two drugs are based on a completely different pharmacological effect and mechanism of action, a common effect is expected. Although their anti-tumor and cytokine inhibitory effects have been proven by respective experiments, an additive or synergistic effect of the two drugs has yet to be reported. Therefore, in the present study, the effects of the COX-2 inhibitor, etodolac, and the non-specific immunostimulant, PSK, were evaluated through in vivo experiments.

Animal experiments were conducted using a COX-2 inhibitor. In their study, Ogata et al measured and reviewed subcutaneously implanted tumors. Nimesulid was found to induce apoptosis, but did not show any tumor reduction effect, although it had an effect on weight gain and prolongation of survival. When 5-FU was used in combination with nimesulid, a tumor reduction effect, weight gain, and prolongation of survival were observed in the $20 \mathrm{mg} / \mathrm{kg} /$ day administration group (13).

Ishizaki et al infused cancer cells into the spleen, and nimesulid or etodolac was administered, respectively. The number of hepatic metastatic lesions were then assessed. Etodolac reduced the number of hepatic metastatic lesions, whereas nimesulid did not show such a tendency. As regards the cause, the authors demonstrated that etodolac, compared with nimesulid, inhibits the expression of COX-2 within the tumor more strongly, and inhibits the expression of MMP-9 (14).

As shown above, the reproducibility of the effects of a COX-2 inhibitor was confirmed by the experiments conducted using etodolac with tumor-reducing effect.

In Japan, PSK is commonly administered as a non-specific immunostimulant. PSK is known to have effects such as an increase in immune capacity, an increase in ability to produce TNF- $\alpha$, inhibition of excessive production of IL- 6 , inhibition of TGF- $\beta$, and inhibition of MMP activity. It is also known 
to have clinical effects in combined use for postoperative adjuvant chemotherapy for stomach $(15,16)$ and colon $(17-19)$ cancers.

The two drugs, PSK and etodolac, exhibited common pharmacological effects such as the inhibition of cytokines and MMP activity, although their mechanism of action varied. Thus, experiments to were conducted ascertain whether the combined use of the two drugs had particular effects or not and examined the number of hepatic metastases and serological factors.

In this experiment, etodolac produced a decrease in the number of hepatic metastases, but no significant difference was observed. Thus, the reproducibility of the findings of Ishizaki et al was not confirmed. In contrast, the number of hepatic metastases following treatment with PSK was significantly reduced, and combined use showed an inhibitory but not a synergistic effect.

Regarding serological factors, the MMP-9 level was significantly inhibited by any of the drugs administered singly, while combined use did not show any synergistic effect. Etodolac and PSK strongly showed an inhibitory effect on MMP-9.

When used as a single drug, a weak effect on IL-6 and TGF- $\beta$ was observed, and an inhibitory effect was confirmed only when used in combination. Thus, the clinical significance of the combined use of the two drugs was identified.

Yoshino et al investigated the combined use with 5-FU, and found that nimesulid has a combined inhibitory effect on tumor growth. Therefore, weight gain and survival were affected due to the inhibition of hypercytokinemia caused by the side effects of 5-FU. In contrast, it was reported that postoperative adjuvant chemotherapy when combined with PSK for stomach or colon cancers improved the immune capacity decreased by surgery or anti-tumor drugs, while a reduction in side effects by the inhibition of hypercytokinemia was considered (20). Findings of the present study showed that the combined use of PSK or COX-2 is likely to increase this effect and may be used in the clinical setting in the future.

\section{References}

1. Yoshimatsu K, Golijanin D, Paty PB, et al: Inducible microsomal prostaglandin $\mathrm{E}$ synthase is overexpressed in colorectal adenomas and cancer. Clin Cancer Res 7: 3971-3976, 2001.

2. Takeda H, Sonoshita M, Oshima H, et al: Cooperation of cyclooxygenase 1 and cyclooxygenase 2 in intestinal polyposis. Cancer Res 63: 4872-4877, 2003.

3. Seno H, Oshima M, Ishikawa T, et al: Cyclooxygenase-2 and prostaglandin $\mathrm{E}_{2}$ receptor $\mathrm{EP}_{2}$-dependent angiogenesis in $\mathrm{Apc}^{\Delta 716}$ mouse intestinal polyps. Cancer Res 62: 506-511, 2002.
4. Tsujii M, Kawano S and DuBois RN: Cyclooxygenase-2 expression in human colon cancer cells increase metastatic potential. Proc Natl Acad Sci USA 94: 3336-3340, 1997.

5. Tomozawa $\mathrm{S}$, Nagawa $\mathrm{H}$, Tsuno $\mathrm{N}$, et al: Inhibition of haematogenous metastasis of colon cancer in mice by a selective COX-2 inhibitor, JTE-522. Br J Cancer 81: 1274-1279, 1999.

6. Kune GA, Kune S and Watson LF: Colorectal cancer risk, chronic illness, operations, and medications: case control results from the Melbourne Colorectal Cancer Study. Cancer Res 48: 4399-4404, 1988.

7. Matsunaga N, Yamada $\mathrm{N}$ and Hirakawa K: Combined treatment with fluorinated pyrimidines and selective cyclooxygenase-2 inhibitor for liver metastasis of colon cancer. Nippon Rinsho 61: 487-489, 2003 (In Japanese).

8. Zhang H, Morisaki T, Matsunaga H, et al: Protein-bound polysaccharide PSK inhibits tumor invasiveness by down-regulation of TGF- $\beta 1$ and MMPs. Clin Exp Metastasis 18: 343-352, 2000.

9. Irie T, Tsujii $M$ and Tsuji S: The effect of COX on tumor progression. Ganchiryou to Shukushu Frontiers in Cancer Treatment 16: 17-21, 2004.

10. Peluffo GD, Stillitani I, Rodriguez VA, et al: Reduction of tumor progression and paraneoplastic syndrome development in murine lung adenocarcinoma by nonsteroidal anti-inflammatory drugs. Int J Cancer 110: 825-830, 2004.

11. Bresalier RS, Sandler RS, Quan H, et al: Cardiovascular events associated with rofecoxib in a colorectal adenoma chemoprevention trial. N Engl J Med 352: 1092-1102, 2005.

12. Kerr DJ, Dunn JA, Langman MJ, et al: Rofecoxib and cardiovascular adverse events in adjuvant treatment of colorectal cancer. N Engl J Med 357: 360-369, 2007.

13. Ogata J, Sakamoto N, Hisada M, Wada T, Kato K, Aoki T and Koyanagi Y: Experimental study on the antitumor effect of a selective cyclooxygenase-2 inhibitor combined with 5-fluorouracil in a mouse model of colon cancer. J Tokyo Med Univ 61: 336-345, 2003.

14. Ishizaki T, Katsumata K, Tsuchida A, et al: Etodolac, a selective cyclooxygenase-2 inhibitor, inhibits liver metastasis of colorectal cancer cells via the suppression of MMP-9 activity. Int J Mol Med 17: 357-362, 2006.

15. Nakazato H, Koike A, Saji S, Ogawa N and Sakamoto J: Efficacy of immunochemotherapy as adjuvant treatment after curative resection of gastric cancer. Lancet 343: 1122-1126, 1994.

16. Toge $T$ and Yamaguchi Y: Protein-bound polysaccharide increases survival in resected gastric cancer cases stratified with a preoperative granulocyte and lymphocyte count. Oncology 7 : 1157-1161, 2000.

17. Ohwada S, Ikeya T, Yokomori T, et al: Adjuvant immunochemotherapy with oral Tegafur/Uracil plus PSK in patients with stage II or III colorectal cancer: a randomized controlled study. Br J Cancer 90: 1003-1010, 2004.

18. Yoshitani S and Takashima S: Efficacy of postoperative UFT (Tegafur/Uracil) plus PSK therapies in elderly patients with resected colorectal cancer. Cancer Biother Radiopharm 24: 35-39, 2009.

19. Sakamoto J, Morita S, Oba K, Matsui T, Kobayashi M, Nakazato H and Ohashi Y: Efficacy of adjuvant immunochemotherapy with polysaccharide $\mathrm{K}$ for patients with curatively resected colorectal cancer: a meta-analysis of centrally randomized controlled clinical trials. Cancer Immunol Immunother 55: 404-411, 2006.

20. Yoshino S, Hazama S, Shimizu R, et al: Immunoregulatory effects of PSK on the balance between Th1 and Th2 in patients with colorectal cancer. Biotherapy 17: 26-31, 2003. 